\title{
Overexpression of phosphatidylinositol 4-kinase type Illa is associated with undifferentiated status and poor prognosis of human hepatocellular carcinoma
}

\author{
Adeodat Ilboudo ${ }^{1,3,4 \dagger}$, Jean-Charles Nault5,6+, Hélène Dubois-Pot-Schneider ${ }^{2,3,4}$, Anne Corlu²,3,4, \\ Jessica Zucman-Rossi ${ }^{5,6}$, Michel Samson ${ }^{1,3,4}$ and Jacques Le Seyec ${ }^{1,3,4^{*}}$
}

\begin{abstract}
Background: Hepatocellular carcinoma (HCC) is a particularly severe disease characterized by a high rate of recurrence and death even after surgical resection. Molecular characterization of HCC helps refine prognosis and may facilitate the development of improved therapy. Phosphatidylinositol 4-kinases have recently been identified as cellular factors associated with cancer. Also, phosphatidylinositol 4-kinase type IIla (PI4KA) is necessary for the propagation of the hepatitis C virus, a major etiological factor for HCC.

Methods: Reverse transcription, quantitative real-time PCR was used to assay PI4KA mRNA. The expression levels were investigated both in a collection of molecularly and clinically characterized hepatic tissues from 344 patients with diverse liver diseases and in human hepatocyte cell lines whose proliferative and differentiation status was controlled by specific culture conditions. Analytical microarray data for $60 \mathrm{HCC}$ and six normal liver tissue samples were exploited to study correlations between PI4KA mRNA levels and cell proliferation markers in vivo. Postoperative disease-specific survival and time to recurrence in a set of 214 patients with HCC were studied by univariate and multivariate analyses.

Results: PI4KA mRNA was more abundant in HCC than normal healthy tissues. This upregulation correlated significantly with both poor differentiation and the active proliferation rate in HCC. These associations were confirmed with in vitro models. Moreover, patients with HCC who had been treated by surgical resection and had higher PI4KA mRNA concentrations in their tumor tissue exhibited a higher risk of tumor recurrence (median time: 20 months versus 49 months, $P=0.0012$ ) and shorter disease-specific survival (first quartile time: 16 months versus 48 months, $P=0.0004$ ). Finally, the abundance of PI4KA mRNA proved to be an independent prognostic marker of survival for cases of HCC (hazard ratio $=2.36, \mathrm{P}=0.0064$ ).

Conclusions: PI4KA mRNA could be used as a new molecular marker to improve established prognostic models for HCC. These findings also indicate possible new lines of research for the development of innovative therapeutic approaches targeting PI4KA.
\end{abstract}

Keywords: Hepatocellular carcinoma, PI4KA, Biomarker, Prognosis

\footnotetext{
*Correspondence: jacques.leseyec@univ-rennes1.fr

${ }^{\dagger}$ Equal contributors

'INSERM, UMR-1085, Institut de Recherche Santé Environnement \& Travail (IRSET), F-35043, Rennes, France

${ }^{3}$ Université de Rennes 1, F-35043, Rennes, France

Full list of author information is available at the end of the article
} 


\section{Background}

Liver cancers are the third leading cause of death by cancer worldwide, and are the sixth most common group of malignancies [1]. Hepatocellular carcinoma (HCC) is the most common primary cancer of the liver (70-80\%), more frequent than cholangiocarcinoma, and is more frequent in men than in women [2]. It rarely occurs in normal liver. In western countries, HCC mostly affects patients already suffering from cirrhosis due to chronic alcohol intake, or to chronic hepatitis $\mathrm{B}$ virus (HBV) or hepatitis $\mathrm{C}$ virus (HCV) infections [3]. Some cases of HCC emerge by malignant transformation of hepatocellular adenomas (HCA). HCA are benign hepatocellular tumors that develop mostly in otherwise normal liver in women taking oral contraception [4]. Classifications for HCA and HCC, based on their molecular signatures, have been established to refine prognosis and to facilitate work to develop targeted therapies. Thus, a genotype/phenotype classification identified five different molecular subgroups of HCA: (i) hepatocyte nuclear factor 1 homeobox A (HNF1A) mutated, (ii) inflammatory, (iii) catenin (cadherin-associated protein) beta 1 (CTNNB1) mutated, (iv) inflammatory and CTNNB1 mutated, and (v) unclassified. The presence of mutations in the CTNNB1 gene is a factor for poor prognosis, as they are associated with a high risk of malignant transformation of HCA to HCC [5,6]. Several transcriptomic classifications of HCC provide evidence of the substantial genetic and phenotypic heterogeneity of this tumor type [7]. One of these classifications individualizes six molecular subgroups (G1 to G6) related to clinical and pathological features [8]. However, the mechanisms underlying the molecular and phenotypic differences between HCCs remain to be deciphered.

There has been growing interest in phosphatidylinositol 4-kinase type III $\alpha$ (PI4KA) and its involvement in liver disease. We and others have shown that this enzyme is required for the propagation of $\mathrm{HCV}$, one of the main etiological factors of HCC [9-13]. Four different phosphatidylinositol 4-kinases (PI4Ks) are expressed in human cells [14]. These isoenzymes (PI4KA, PI4KB, PI4K2A and PI4K2B) catalyze the phosphorylation of phosphatidylinositol (PtdIns) in the cytoplasmic face of cellular membranes, leading to the production of phosphatidylinositol 4-phosphate (PtdIns4P). Each isozyme displays a specific subcellular distribution. Thus, PI4KA is mainly found in the endoplasmic reticulum (ER). Its activity seems to regulate both the formation of ER exit sites $[15,16]$ and the concentration of PtdIns4P in the plasma membrane [17]. PtdIns4P is a precursor of other phosphoinositides (PIs), generated by additional phosphorylation(s), involved in a wide range of cellular functions [18]. For example, cell migration and proliferation are controlled by PI-dependent signaling pathways involving phospholipase C (PLC) isozymes or phosphoinositide 3- kinases. Therefore, it is unsurprising that some cancers are associated with various types of deregulation in these signaling pathways, including those affecting PI4Ks [19].

The analysis of PI4KA expression in various liver diseases may therefore be informative. It may improve the molecular characterization of $\mathrm{HCC}$, providing diagnostic and prognostic tools, and may even be useful to adapt and improve therapy. Moreover, the importance of PI4KA to the HCV life cycle makes it a potential therapeutic target. However, any treatment targeting PI4KA may be affected by its expression. In this context, we investigated PI4KA expression in large cohort of liver diseases. Because antibodies suitable for the detection of the endogenous protein by immunohistochemistry are not available, we used quantitative RT-PCR to assay PI4KA mRNA. We found that the PI4KA gene was more strongly expressed in HCC than in normal liver. This expression was correlated with the differentiation status. PI4KA also appeared to be an independent marker of an unfavorable prognosis in HCC.

\section{Methods \\ Biological materials}

All patients gave written consent as required by French law. This study was approved by our local IRB committees (CCPRB for "Comité Consultatif de Protection des Personnes dans la Recherche Biomédicale" Paris Saint Louis and CPP for "Comité de Protection des Personnes" Ouest V). Liver tissues were collected in French hospitals and immediately frozen in liquid nitrogen after surgical resection. The first library included a total of 344 liver samples with five normal and 339 pathological tissues (21 cirrhosis, $101 \mathrm{HCA}$ and $217 \mathrm{HCC}$ ). Two additional normal tissue samples were used as calibrators for the relative levels of transcripts in samples as determined by quantitative RT-PCR. The molecular subtype of each of the $101 \mathrm{HCA}$ (see Additional file 1 for clinical and molecular features) was determined according to an established molecular classification using gene mutation and immunohistochemistry staining [4-6]. The set of 217 HCC included in this study has already been extensively described (the main clinical, pathological and molecular features are presented in Additional file 2) [20]. All HCC were screened for TP53 and CTNNB1 mutations and were classified using the G1-G6 molecular classification as previously described $[8,21]$. The second cohort consisted of liver fragments from 31 patients who underwent surgical resection for hepatic metastases; these fragments were taken in macroscopically normal liver at a distance from the metastasis.

Huh-7.5.1 and HepaRG cell cultures were maintained as previously described and were subjected to specific differentiation protocols [22,23]. Huh-7.5.1 cells were seeded at a density of $6 \times 10^{4}$ per $\mathrm{cm}^{2}$ in standard 
medium, consisting of complete DMEM (Life Technologies) supplemented with $100 \mathrm{U} / \mathrm{ml}$ penicillin (Life Technologies), $100 \mu \mathrm{g} / \mathrm{ml}$ streptomycin (Life Technologies), $2 \mathrm{mM}$ L-glutamine (Life Technologies), $10 \mathrm{mM}$ HEPES (Life Technologies), nonessential amino acids (SigmaAldrich) and $10 \%$ heat-inactivated fetal bovine serum (Hyclone, Logan, UT, USA). When the culture reached 95\% confluence, defined as day 0 (D0), the standard culture medium was supplemented with $1 \%$ dimethyl sulfoxide (DMSO, Sigma-Aldrich) for 6 consecutive days. Cells were collected on days 0, 1, 3 and 6 (D0, D1, D3 and D6, respectively). HepaRG cells were seeded at a density of $2.7 \times 10^{4}$ per $\mathrm{cm}^{2}$ on day 0 and maintained for two weeks in William's E medium (Life Technologies) supplemented with $100 \mathrm{U} / \mathrm{ml}$ penicillin (Life Technologies), $100 \mu \mathrm{g} / \mathrm{ml}$ streptomycin (Life Technologies), $5 \mu \mathrm{g} / \mathrm{ml}$ insulin (Sigma-Aldrich), $50 \mu \mathrm{M}$ hydrocortisone hemisuccinate (Roussel) and 10\% fetal bovine serum (Hyclone, Logan, UT, USA). Then, the culture medium was or was not supplemented with $2 \%$ DMSO (Sigma-Aldrich) for two additional weeks. Cells were collected at days 4, 15 and 30 post-seeding (D4, D15 and D30, respectively). D30- and D30+ indicate that cells were cultured without DMSO for 30 days or without DMSO for 15 days and then with 2\% DMSO for 15 days, respectively.

\section{Quantitative RT-PCR and microarray analysis}

DNA and RNA were purified with commercial kits (Qiagen). Quantitative RT-PCR and its data analysis were performed as previously described [24]. TaqMan gene expression assays (hs99999901_s1 and hs01021084m1, Applied Biosystems) were used to analyze 18S and PI4KA expression, respectively. The last assay detected both PI4KA mRNA variants referenced in GenBank (NM_058004.3 = Variant 1, NM_002650.2 = Variant 2) with no amplification of pseudogene products. The probe hybridizes at the exon-exon junctions $39-40$ and $7-8$ of variants 1 and 2, respectively. For absolute quantification, a plasmid (pCMV-SPORT6-hPI4KA, Open Biosystems) containing the PI4KA cDNA (BC018120) was used for calibration. The sequences of the other primers used are given in Additional file 3. The microarray data (60 HCC and 6 normal livers) have been extensively described previously [8] and are available on a public database (E-TABM-36).

\section{Statistics}

Continuous data were compared using the non-parametric Mann-Whitney Test (two groups) or Kruskal-Wallis Test (more than two groups). Spearman or Pearson tests were used for correlation analysis according to sample size. We used the Mantel Cox log rank test and Kaplan Meier method to assess post-resection survival. Disease-specific survival is defined by the tumor-related death and patients who died of another etiology were censored. Recurrencefree survival was defined as the length of time after hepatectomy for HCC during which a patient survives with no sign of HCC. The last recorded follow-up visit was in February 2011. Univariate analysis using Cox models was performed to identify variables associated with disease-specific survival. Variables with a $\mathrm{P}$ value $<0.05$
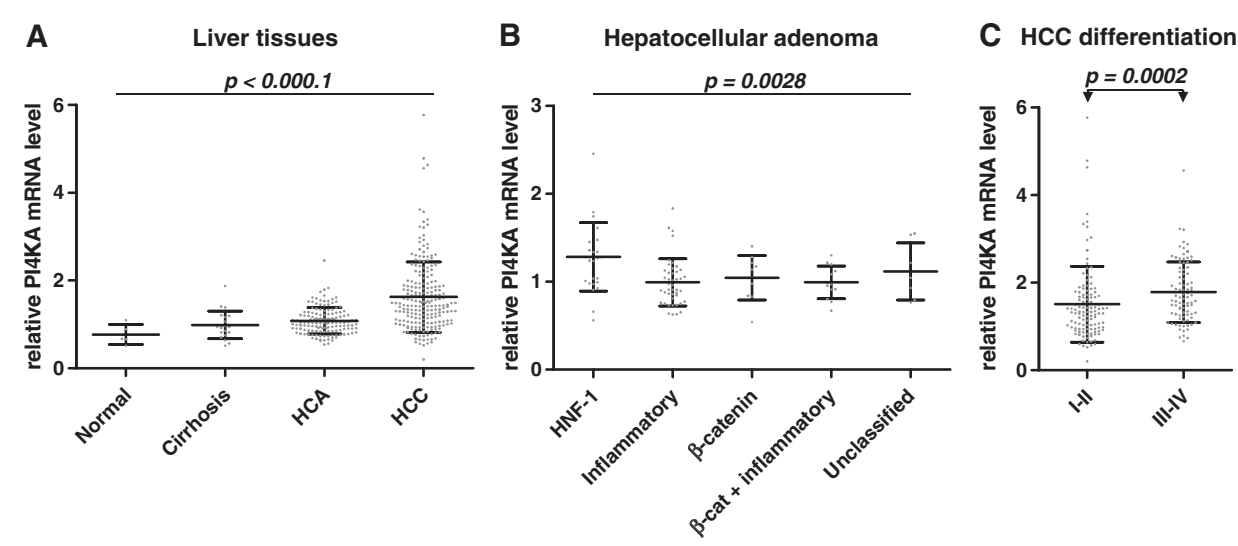

Figure 1 PI4KA transcript abundance in human liver samples of various subtypes. Scatter plots show the PI4KA mRNA levels in human liver tissues as assayed by RT-real time PCR. Values represent the gene expression of each sample relative to the mean value for two control samples from normal hepatic tissues. The 18S RNA levels were used for normalization. Means with standard deviations are indicated for each sample category. $P$ values from Kruskal-Wallis tests (more than two groups, panels $\mathbf{A}$ and $\mathbf{B}$; black line) or Mann-Whitney U-tests (two groups, panel $\mathbf{C}$; black line with arrows) are indicated. (A) Comparison between normal hepatic tissue $(n=5)$, cirrhotic tissue $(n=21)$, and benign $(H C A$, $n=101$ ) and malignant (HCC, $n=217$ ) hepatocellular tumors. (B) Expression in different hepatocellular adenoma (HCA) groups subdivided into adenomas inactivated for HNF1A $(n=27)$, inflammatory adenomas $(n=44), \beta$-catenin-activated adenomas $(n=10)$, inflammatory and $\beta$-catenin-activated adenomas $(n=13)$ and unclassified adenomas $(n=7)$. (C) Expression compared according to the differentiation grade of HCC grouped according to the Edmonson classification (Grades I-II, $n=118$; Grades III-IV, $n=88$ ). 
in the univariate analysis were entered into a Cox multivariate model. $\mathrm{P}$ values $<0.05$ were considered as significant. Statistical analysis was performed using Graphpad Prism and R statistical software (http://www. R-project.org/).

This study adheres to the REMARK guidelines [25].

\section{Results and discussion}

PI4KA transcript levels in pathological human livers

A liver tissue library of 344 characterized samples was exploited to compare PI4KA transcript levels in normal and various pathological hepatic tissues (Figure 1A). There were no significant differences between normal and cirrhosis samples. PI4KA mRNA was slightly more abundant in HCA than in normal samples (1.4-fold; Mann-Whitney test: $P=0.0235)$. We therefore tested for differences between the different HCA subgroups classified according to their specific pathomolecular signature (Figure 1B) [4-6]. PI4KA mRNA levels were higher in HCA with mutations in HNF1A gene than other HCA subgroups. The HNF1A gene encodes the hepatocyte nuclear factor 1-alpha, involved in hepatocyte differentiation [26].

The level of PI4KA transcripts was 2.1 times higher (Mann-Whitney test: $P=0.0023$ ) in HCC than normal reference samples (Figure 1A). The PI4KA mRNA values, however, did not differ significantly between HCC from patients with and without chronic HCV infection (data not shown). This is consistent with the observation that $\mathrm{HCV}$ promotes its replication by stimulating the activity of PI4KA but not the expression of its gene [27].

Influence of differentiation/proliferative status of cancerous liver cells on PI4KA transcript levels

The overexpression of PI4KA in HCC could not be explained by HNF1A mutations: the frequency of these

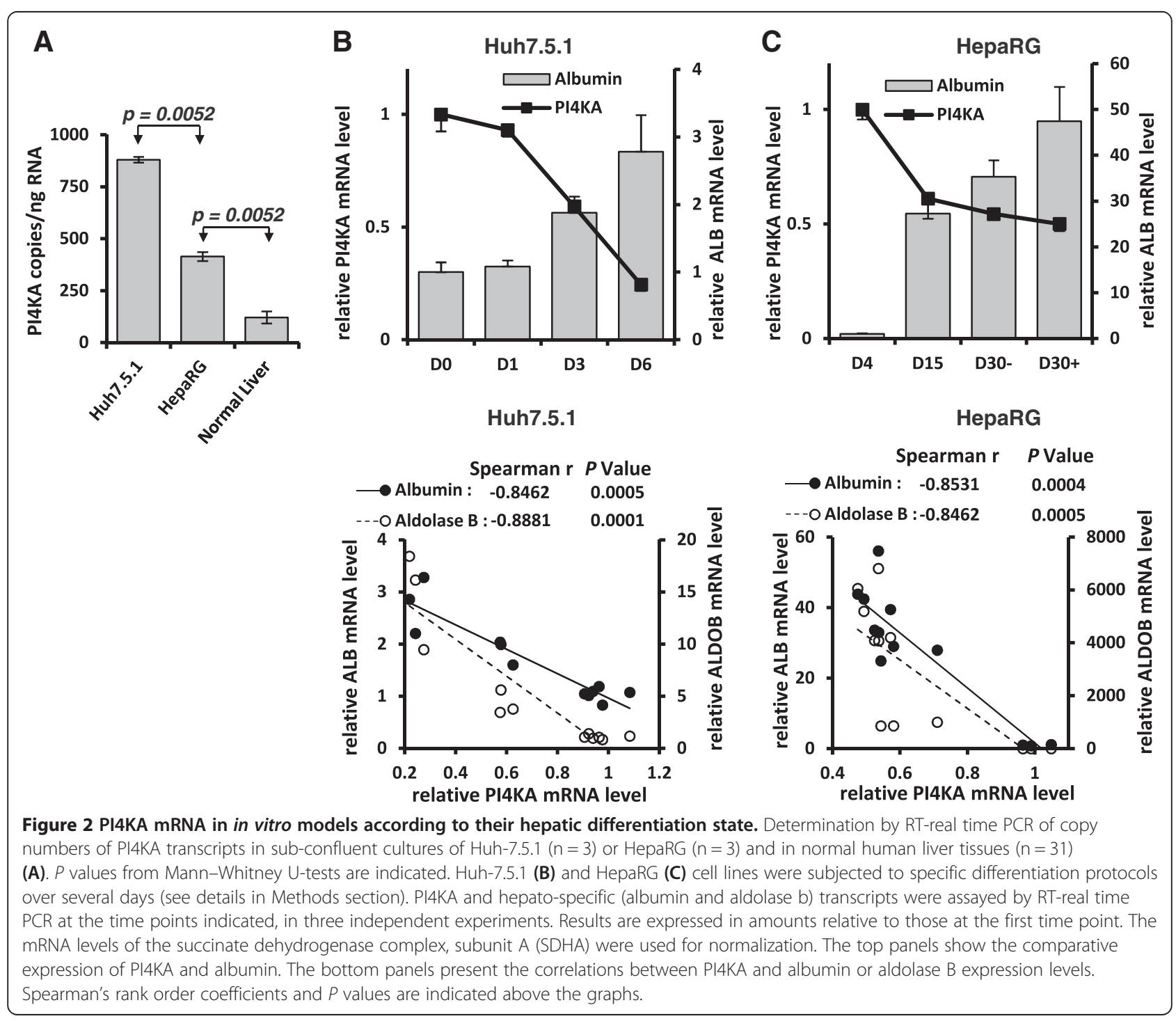



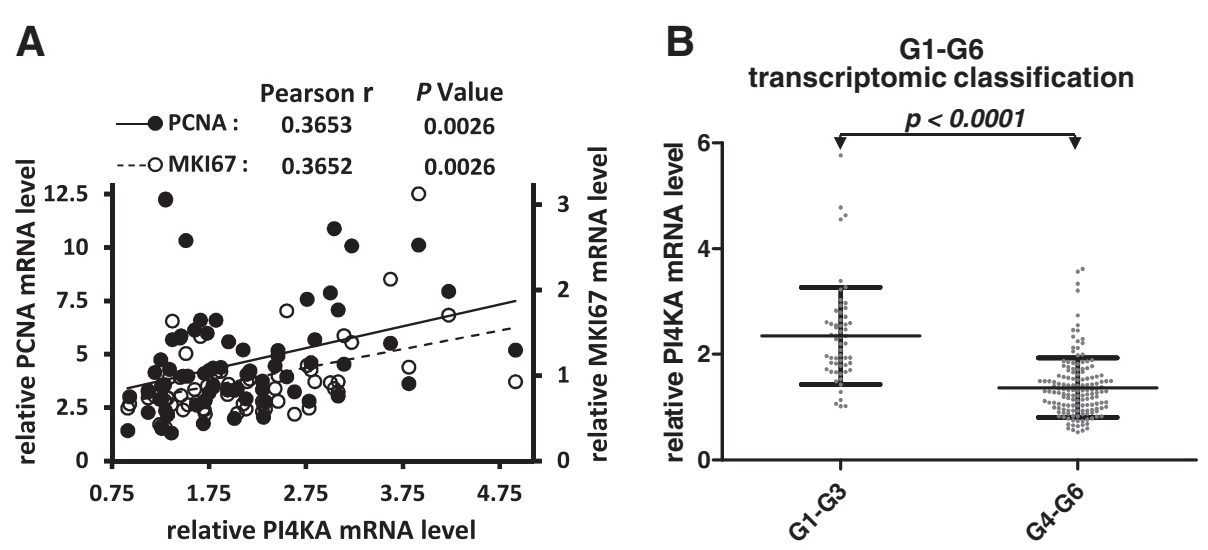

Figure 3 Correlation between PI4KA expression level, proliferative markers and molecular status of HCC. A correlation study between PI4KA expression levels and PCNA or MKI67 expression levels was performed in 60 HCC and 6 normal liver tissues analyzed with the HG-U133A Affymetrix GeneChip ${ }^{\mathrm{TM}}$ microarray. Pearson's rank order coefficients and $P$ values are indicated for the correlations (A). Scatter plots show the PI4KA mRNA as assayed by RT-real time PCR in HCC specimens stratified according to transcriptomic classification (G1-G3, $n=58 ; \mathrm{G} 4-\mathrm{G} 6, \mathrm{n}=149$ ) (B). Values represent the gene expression of each sample relative to the mean value for two control samples from normal hepatic tissues. The $18 \mathrm{~S}$ RNA levels were used for normalization. Means with standard deviations are indicated for each sample category. The $P$ value from a Mann-Whitney U-test is indicated.

mutations was low in our HCC series $(<4 \%)$ [28]. By contrast, the mutation of this hepatic differentiation factor was associated with upregulation of PI4KA mRNA in HCA. We therefore looked for an association between the differentiation state of HCC and amounts of the PI4KA transcript. We found that the less differentiated HCC, according to the Edmonson classification, showed stronger PI4KA expression (compare grades I-II with grades III-IV in Figure 1C).

To study the link between hepatic differentiation and PI4KA mRNA level further, we used two wellestablished in vitro models based on HCC derived cell lines (Huh-7.5.1 derived from Huh-7 [23]; and HepaRG) whose differentiation state can be controlled $[22,29]$. We compared the absolute amounts of PI4KA mRNA in
Huh-7.5.1 cells, HepaRG cells and normal liver tissue. Normal human hepatic specimens, from a cohort different from that used in the analysis described above (presented in Figure 1), contained an average of $121.71 \pm$ 28.59 PI4KA cDNA copies/ng of total RNA (Mean \pm SD); HepaRG and Huh-7.5.1 cells, both at proliferative stages, had respectively 3.4-fold and 7.2-fold more PI4KA transcripts (Figure 2A). Thus, as in HCC from which these cell lines derive, a similar up-regulation of PI4KA transcripts was detected. Furthermore, the quantity of this mRNA was highest in the most dedifferentiated cell line (Huh-7.5.1). By applying their specific differentiation procedures, both cell lines gradually acquired a more differentiated hepatocyte state, as evidenced by the up-regulation of the liver-specific ALDOB

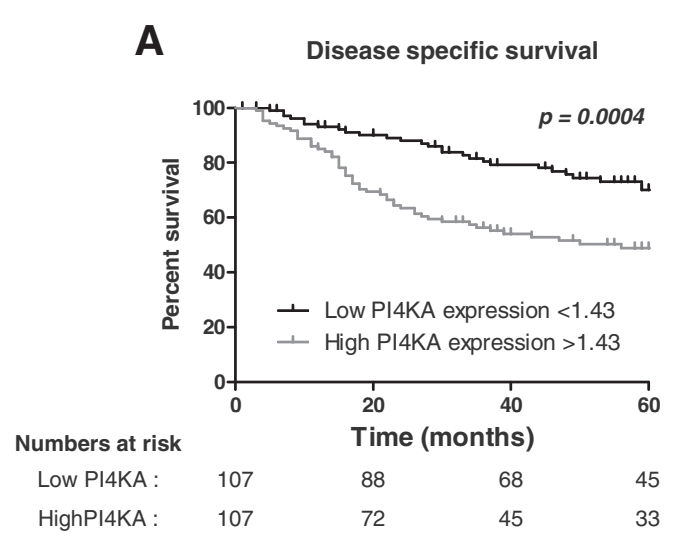

B Recurrence-free survival

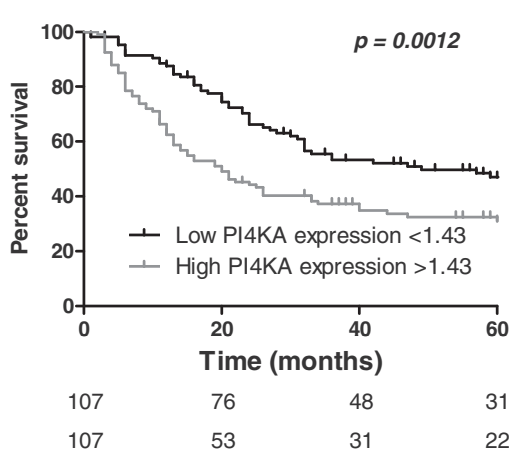

Figure 4 Mantel-Cox survival curves. The Kaplan Meier method and Log-Rank test were applied to data for 214 patients with HCC classified into two groups according to whether the PI4KA expression value was above or below the median (low- or high-amount of PI4KA mRNA). A and B panels present disease-specific survival (tumor-related death) and tumor recurrence-free survival, respectively. $P$ values are indicated. Numbers at risk are indicated below each panel. 
gene encoding aldolase B and ALB gene encoding albumin. By contrast, the PI4KA transcripts levels gradually decreased during differentiation (Figure $2 \mathrm{~B}$ and $\mathrm{C}$, top panels). Spearman rank analysis showed that PI4KA mRNA quantities in Huh-7.5.1 and HepaRG cells were negatively correlated with the ALDOB and ALB mRNA quantities (Figure $2 \mathrm{~B}$ and $\mathrm{C}$, bottom panels). Given that the differentiated state of both cell lines is clearly associated with a decline in proliferative activity [29,30], our data indicate that an increase in the number of PI4KA transcripts correlates with hepatic dedifferentiation and active proliferation.

High mitotic activity and proliferation rate are also frequently associated with poor differentiation in cancer. We therefore tested for a relationship between PI4KA expression and two commonly used markers of cell proliferation (proliferating cell nuclear antigen [PCNA] and MKI67) in a series of $60 \mathrm{HCC}$ and six normal liver tissue samples analyzed with the HG-U133A Affymetrix Gene$\mathrm{Chip}^{\mathrm{Tw}}$ microarray. PI4KA expression was partly but significantly correlated with PCNA and MKI67 expression in HCC (Figure $3 \mathrm{~A}$ and $\mathrm{B}$ ). This was corroborated by the observation that the level of PI4KA mRNA was higher in HCC classified in G1-G3 subgroups than in HCC classified in G4-G6 subgroups (Figure 3B). Indeed, the G1-G3 subgroups are known as the proliferative subclasses because they display transcriptomic dysregulation of cell cycle genes [8,31]; they are also typically enriched in poorly differentiated HCC $(66 \%$ of HCC in G1-G3 subgroups have an Edmonson grade III-IV versus 35\% of HCC in G4-G6 subgroups, $P=0.0001$, Fisher's exact test), such as those carrying TP53 mutations and those with high level of serum AFP, both factors correlating with stronger expression of PI4KA (Additional file 4). Thus, in vivo and in vitro data sets were consistent and suggest that the quantity of PI4KA transcripts is related to the differentiation status and the proliferation rate of tumors.
While PI4K2A has been shown to be up-regulated in at least seven types of human cancer [32], our work reports for the first time a rise of PI4KA transcript levels in a human carcinoma. The reason of this up-regulation in HCC remains to be determined. However, studies suggest that PI4KA may regulate signaling pathways involved in survival and proliferation [19].

\section{Prognostic significance of PI4KA transcript upregulation}

The annotation of our HCC library includes clinical outcomes, and in particular survival and recurrence data, so we cross-checked these data with PI4KA mRNA expression levels. The 214 HCC samples were subdivided into two groups with respectively low or high amounts of PI4KA mRNA. These groups were stratified by the median value. Patients with highest rate of PI4KA mRNA had shorter disease-specific survival: the first quartile of time to tumor-related death was 16 months for HCC with high PI4KA mRNA level, and 48 months for HCC with low PI4KA mRNA level $(p=0.0004$, Figure 4A). Similar results were obtained for the risk of tumor recurrence: medians time to tumor recurrence were 20 months for the group with the highest amounts of PI4KA mRNA and 49 months for the other group of patients $(p=0.0012$, Figure $4 B)$. Multivariate analysis indicated that high amount of PI4KA mRNA was associated with disease specific survival (HR: 2.36 (1.27; 4.36), $p=$ $0.006415)$, independently of classical clinical, biological and pathological features such as size, number of tumors, microvascular invasion, and tumor portal thrombosis (Table 1). This type of association between PI4KA up-regulation and poor prognosis has been suggested by comparisons of cancer cell lines derived from hamster pancreas: PI4KA was more strongly expressed in the most aggressive cell line [33]. PI4KA could therefore serve as a prognostic marker, in addition to those already identified, and may help improve the accuracy of existing prediction models [20]. Further investigations

Table 1 Univariate and multivariate analysis of clinical, pathological and molecular variables for disease-specific survival in 214 HCC

\begin{tabular}{|c|c|c|c|c|c|c|}
\hline \multirow[b]{2}{*}{ Variables } & \multicolumn{3}{|c|}{ Univariate analysis } & \multicolumn{3}{|c|}{ Multivariate analysis } \\
\hline & HR & $95 \% \mathrm{Cl}$ & $P$ & HR & $95 \% \mathrm{Cl}$ & $P$ \\
\hline Cirrhosis & 1.45 & $0.90-2.31$ & 0.119 & - & - & - \\
\hline Multiple tumors & 1.952 & $1.09-3.49$ & 0.024 & 3.53 & $1.83-6.81$ & 0.000167 \\
\hline $\mathrm{HCC}>5 \mathrm{~cm}$ & 1.705 & $1.04-2.80$ & 0.035 & 1.88 & $1.01-3.47$ & 0.044943 \\
\hline AFP $>20 \mathrm{ng} / \mathrm{ml}$ & 2.04 & $1.25-3.32$ & 0.0043 & 1.58 & $0.90-2.76$ & 0.107818 \\
\hline Microvascular invasion & 2.98 & $1.86-4.78$ & $5.83 e-06$ & 1.98 & $1.09-3.60$ & 0.024328 \\
\hline Tumor portal thrombosis & 3.59 & $2.14-6.01$ & $1.21 \mathrm{e}-06$ & 1.92 & $1.01-3.66$ & 0.045599 \\
\hline Differentiation: Edmonson III/IV & 1.60 & $1.01-2.52$ & 0.0436 & 0.88 & $0.50-1.54$ & 0.653579 \\
\hline PI4KA high level & 2.22 & $1.39-3.54$ & 0.000823 & 2.36 & $1.27-4.36$ & 0.006415 \\
\hline
\end{tabular}

Bold values represent $P$ values considered to be statistically significant $(<0.05)$. HR: hazard ratio; Cl: confidence interval. 
are required to elucidate the role of this phospholipid kinase in HCC and to assess whether it is a potential targeted for therapy.

\section{Conclusions}

Our study clearly shows that PI4KA transcripts are more abundant in HCC than normal liver tissue, and that this upregulation is correlated to their differentiation/proliferation status and is associated with poor survival. Further work is needed to determine the involvement, if any, of PI4KA in HCC pathogenesis.

\section{Additional files}

\section{Additional file 1: Clinical and molecular features of hepatocellular} adenomas.

Additional file 2: Characteristics of 217 patients with hepatocellular carcinoma.

Additional file 3: Primer sequences.

Additional file 4: Correlation between PI4KA mRNA amount and markers of HCC differentiation status. Scatter plots show the PI4KA mRNA levels in HCC samples as assayed by RT-real time PCR. Values represent the gene expression of each sample relative to the mean value for two control samples from normal hepatic tissues. The 18S RNA levels were used for normalization. Means with standard deviation are shown for each sample category. P values from a Mann-Whitney U-test are indicated. Expression according to TP53 mutation status (NM: not mutated, $n=175$; M: mutated, $n=40$ ) (A) or to serum AFP level (AFP $<20 \mathrm{ng} / \mathrm{ml}, n=109$; AFP $>24 \mathrm{ng} / \mathrm{ml}, \mathrm{n}=85)(B)$.

\section{Abbreviations}

HCC: Hepatocellular carcinoma; HBV: Hepatitis B virus; HCV: Hepatitis C virus; HCA: Hepatocellular adenoma; HNF1A: Hepatocyte nuclear factor 1 homeobox A; CTNNB1: Catenin (cadherin-associated protein) beta 1; AFP: Alphafetoprotein; TP53: Tumor protein p53; PI4KA: Phosphatidylinositol 4-kinase type IIla; Ptdlns: Phosphatidylinositol; PLC: Phospholipase C; RT: Reverse transcriptase; PCR: Polymerase chain reaction; ALB: Albumin; ALDOB: Aldolase b; PCNA: Proliferating cell nuclear antigen; MKI67: Antigen identified by monoclonal antibody Ki-67.

\section{Competing interests}

The authors declare that they have no competing interests.

\section{Authors' contributions}

Conception and design: AI JCN HDPS AC JZR MS JLS. Acquisition of data: Al, JCN, HDPS, JLS. Analysis and interpretation of data: AI JCN HDPS AC JZR MS JLS. Statistical analysis: JCN, JLS. Critical revision of the manuscript for important intellectual content: AI JCN HDPS AC JZR MS JLS. Technical and material support: Al, JCN, HDPS, JLS. Study supervision: AC JZR MS JLS. All authors read and approved the final manuscript.

\section{Acknowledgements}

We thank Dr. Francis Chisari (Scripps Research Institute, La Jolla, CA, USA) for the Huh-7.5.1 cells and the Biological Resource Centre of Rennes for providing the normal human liver specimens. This work was supported by the Institute National de la Santé et de la Recherche Médicale (INSERM), the University of Rennes 1, the Comité Grand-Ouest de la Ligue contre le Cancer the Ligue Nationale contre le Cancer ("Cartes d'identité des tumeurs" program), IntegraGen (OSEO), HEPTROMIC (FP7), the PAIR-CHC project NoFLIC (funded by INCa and Association pour la Recherche contre le Cancer, $\mathrm{ARC})$, the Réseau national CRB Foie, INCa (WntHCC) and Biolntelligence (OSEO). Al is supported by a fellowship from the Ministère de l'Education and from the ARC. JCN is supported by a grant from the INCa. HDPS is supported by grants from LIV-ES and the Contrat de Plan Etat Région (axe biothérapie).

\section{Author details}

${ }^{1}$ INSERM, UMR-1085, Institut de Recherche Santé Environnement \& Travail (IRSET), F-35043, Rennes, France. ${ }^{2}$ INSERM, UMR-991, Liver Metabolisms and Cancer, F-35033, Rennes, France. ${ }^{3}$ Université de Rennes 1, F-35043, Rennes, France. ${ }^{4}$ Fédération de Recherche BioSit de Rennes, F-35043, Rennes, France. ${ }^{5}$ INSERM, UMR-674, Génomique fonctionnelle des tumeurs solides, IUH, Paris F-75010, France. ' Université Paris Descartes, Labex Immuno-oncology, Sorbonne Paris Cité, Faculté de Médecine, Paris, France.

Received: 11 June 2013 Accepted: 26 November 2013

Published: 6 January 2014

\section{References}

1. Ferlay J, Shin HR, Bray F, Forman D, Mathers C, Parkin DM: Estimates of worldwide burden of cancer in 2008: GLOBOCAN 2008. Int J Cancer 2010, 127(12):2893-2917.

2. El-Serag HB: Hepatocellular carcinoma. The New England journal of medicine 2011, 365(12):1118-1127.

3. Forner A, Llovet JM, Bruix J: Hepatocellular carcinoma. Lancet 2012, 379(9822):1245-1255.

4. Nault JC, Bioulac-Sage P, Zucman-Rossi J: Hepatocellular Benign Tumors-From Molecular Classification to Personalized Clinical Care. Gastroenterology 2013, 144(5):888-902

5. Bioulac-Sage P, Rebouissou S, Thomas C, Blanc JF, Saric J, Sa Cunha A, Rullier A, Cubel G, Couchy G, Imbeaud S, et al: Hepatocellular adenoma subtype classification using molecular markers and immunohistochemistry. Hepatology 2007, 46(3):740-748.

6. Zucman-Rossi J, Jeannot E, Nhieu JT, Scoazec JY, Guettier C, Rebouissou S, Bacq Y, Leteurtre E, Paradis V, Michalak S, et al: Genotype-phenotype correlation in hepatocellular adenoma: new classification and relationship with HCC. Hepatology 2006, 43(3):515-524.

7. Hoshida Y, Toffanin S, Lachenmayer A, Villanueva A, Minguez B, Llovet JM: Molecular classification and novel targets in hepatocellular carcinoma: recent advancements. Semin Liver Dis 2010, 30(1):35-51.

8. Boyault S, Rickman DS, De Reynies A, Balabaud C, Rebouissou S, Jeannot E, Herault A, Saric J, Belghiti J, Franco D, et al: Transcriptome classification of $\mathrm{HCC}$ is related to gene alterations and to new therapeutic targets. Hepatology 2007, 45(1):42-52.

9. Berger KL, Cooper JD, Heaton NS, Yoon R, Oakland TE, Jordan TX, Mateu G, Grakoui A, Randall G: Roles for endocytic trafficking and phosphatidylinositol 4-kinase III alpha in hepatitis $C$ virus replication. Proc Natl Acad Sci U S A 2009, 106(18):7577-7582.

10. Borawski J, Troke P, Puyang X, Gibaja V, Zhao S, Mickanin C, Leighton-Davies J, Wilson CJ, Myer V, Cornellataracido I, et al: Class III phosphatidylinositol 4-kinase alpha and beta are novel host factor regulators of hepatitis $C$ virus replication. J Virol 2009, 83(19):10058-10074.

11. Tai AW, Benita Y, Peng LF, Kim SS, Sakamoto N, Xavier RJ, Chung RT: A functional genomic screen identifies cellular cofactors of hepatitis $C$ virus replication. Cell Host Microbe 2009, 5(3):298-307.

12. Trotard M, Lepere-Douard C, Regeard M, Piquet-Pellorce C, Lavillette D, Cosset FL, Gripon P, Le Seyec J: Kinases required in hepatitis $C$ virus entry and replication highlighted by small interference RNA screening. Faseb J 2009, 23(11):3780-3789.

13. Vaillancourt FH, Pilote L, Cartier M, Lippens J, Liuzzi M, Bethell RC, Cordingley MG, Kukolj G: Identification of a lipid kinase as a host factor involved in hepatitis C virus RNA replication. Virology 2009, 387(1):5-10.

14. Minogue S, Waugh MG: The Phosphatidylinositol 4-Kinases: Don't Call it a Comeback. Subcell Biochem 2012, 58:1-24.

15. Blumental-Perry A, Haney CJ, Weixel KM, Watkins SC, Weisz OA, Aridor M: Phosphatidylinositol 4-phosphate formation at ER exit sites regulates ER export. Dev Cell 2006, 11(5):671-682.

16. Farhan H, Weiss M, Tani K, Kaufman RJ, Hauri HP: Adaptation of endoplasmic reticulum exit sites to acute and chronic increases in cargo load. Embo J 2008, 27(15):2043-2054.

17. Balla A, Kim YJ, Varnai P, Szentpetery Z, Knight Z, Shokat KM, Balla T: Maintenance of hormone-sensitive phosphoinositide pools in the plasma membrane requires phosphatidylinositol 4-kinase Illalpha. Mol Biol Cell 2008, 19(2):711-721.

18. Di Paolo G, De Camilli P: Phosphoinositides in cell regulation and membrane dynamics. Nature 2006, 443(7112):651-657. 
19. Waugh MG: Phosphatidylinositol 4-kinases, phosphatidylinositol 4-phosphate and cancer. Cancer Lett 2012, 325(2):125-131.

20. Nault JC, De Reynies A, Villanueva A, Calderaro J, Rebouissou S, Couchy G, Decaens T, Franco D, Imbeaud S, Rousseau F, et al: A Hepatocellular Carcinoma 5-Gene Score Associated with Survival of Patients Following Liver Resection. Gastroenterology 2013, 145(1):176-187.

21. Laurent-Puig P, Legoix P, Bluteau O, Belghiti J, Franco D, Binot F, Monges $G$, Thomas G, Bioulac-Sage P, Zucman-Rossi J: Genetic alterations associated with hepatocellular carcinomas define distinct pathways of hepatocarcinogenesis. Gastroenterology 2001, 120(7):1763-1773.

22. Gripon P, Rumin S, Urban S, Le Seyec J, Glaise D, Cannie I, Guyomard C, Lucas J, Trepo C, Guguen-Guillouzo C: Infection of a human hepatoma cell line by hepatitis B virus. Proc Natl Acad Sci U S A 2002, 99(24):15655-15660.

23. Zhong J, Gastaminza P, Cheng G, Kapadia S, Kato T, Burton DR, Wieland SF, Uprichard SL, Wakita T, Chisari FV: Robust hepatitis C virus infection in vitro. Proc Natl Acad Sci U S A 2005, 102(26):9294-9299.

24. Rebouissou S, Imbeaud S, Balabaud C, Boulanger V, Bertrand-Michel J, Terce F, Auffray C, Bioulac-Sage P, Zucman-Rossi J: HNF1alpha inactivation promotes lipogenesis in human hepatocellular adenoma independently of SREBP-1 and carbohydrate-response element-binding protein (ChREBP) activation. J Biol Chem 2007, 282(19):14437-14446.

25. McShane LM, Altman DG, Sauerbrei W, Taube SE, Gion M, Clark GM: Reporting recommendations for tumor marker prognostic studies. J Clin Oncol 2005, 23(36):9067-9072.

26. Odom DT, Zizlsperger N, Gordon DB, Bell GW, Rinaldi NJ, Murray HL, Volkert TL, Schreiber J, Rolfe PA, Gifford DK, et al: Control of pancreas and liver gene expression by HNF transcription factors. Science 2004, 303 (5662):1378-1381.

27. Reiss S, Rebhan I, Backes P, Romero-Brey I, Erfle H, Matula P, Kaderali L, Poenisch M, Blankenburg H, Hiet MS, et al: Recruitment and activation of a lipid kinase by hepatitis C virus NS5A is essential for integrity of the membranous replication compartment. Cell Host Microbe 2011, 9(1):32-45.

28. Guichard C, Amaddeo G, Imbeaud S, Ladeiro Y, Pelletier L, Maad IB, Calderaro J, Bioulac-Sage P, Letexier M, Degos F, et al: Integrated analysis of somatic mutations and focal copy-number changes identifies key genes and pathways in hepatocellular carcinoma. Nat Genet 2012. 44(6):694-698.

29. Sainz B Jr, Chisari FV: Production of infectious hepatitis C virus by well-differentiated, growth-arrested human hepatoma-derived cells. J Virol 2006, 80(20):10253-10257.

30. Parent R, Marion MJ, Furio L, Trepo C, Petit MA: Origin and characterization of a human bipotent liver progenitor cell line. Gastroenterology 2004 126(4):1147-1156.

31. Lee JS, Chu IS, Heo J, Calvisi DF, Sun Z, Roskams T, Durnez A, Demetris AJ, Thorgeirsson SS: Classification and prediction of survival in hepatocellular carcinoma by gene expression profiling. Hepatology 2004, 40(3):667-676.

32. Li J, Lu Y, Zhang J, Kang H, Qin Z, Chen C: PI4KIllalpha is a novel regulator of tumor growth by its action on angiogenesis and HIF-1alpha regulation. Oncogene 2010, 29(17):2550-2559.

33. Ishikawa S, Egami H, Kurizaki T, Akagi J, Tamori Y, Yoshida N, Tan X, Hayash $\mathrm{N}$, Ogawa M: Identification of genes related to invasion and metastasis in pancreatic cancer by cDNA representational difference analysis. J Exp Clin Cancer Res 2003, 22(2):299-306.

doi:10.1186/1471-2407-14-7

Cite this article as: llboudo et al:: Overexpression of phosphatidylinositol 4-kinase type IIla is associated with undifferentiated status and poor prognosis of human hepatocellular carcinoma. BMC Cancer 2014 14:7.

\section{Submit your next manuscript to BioMed Central and take full advantage of:}

- Convenient online submission

- Thorough peer review

- No space constraints or color figure charges

- Immediate publication on acceptance

- Inclusion in PubMed, CAS, Scopus and Google Scholar

- Research which is freely available for redistribution

Submit your manuscript at www.biomedcentral.com/submit
C Biomed Central 